\title{
Influence of Mixing Intensity on Lysozyme Crystallization in a Meso Oscillatory Flow Reactor
}

\author{
Filipa Castro, ${ }^{* \dagger \odot}$ António Ferreira, ${ }^{\dagger}$ José A. Teixeira, $^{\dagger}$ and Fernando Rocha ${ }^{\dagger}$ \\ ${ }^{\dagger}$ LEPABE-Laboratory for Process Engineering, Environment, Biotechnology and Energy, Faculty of Engineering of the University of \\ Porto, Rua Roberto Frias, s/n, 4200-465 Porto, Portugal \\ ${ }^{\ddagger} \mathrm{CEB}-$ Centre for Biological Engineering, University of Minho, Campus de Gualtar, 4710-057 Braga, Portugal
}

\begin{abstract}
The influence of mixing intensity on protein crystallization has been investigated for the first time in a meso oscillatory flow reactor (meso-OFR). For this, lysozyme crystallization was studied in batch at different oscillation amplitudes and frequencies. Turbidity was monitored over time to measure induction time and follow the crystallization process. Results suggest that the crystallization mechanism may be characterized by the occurrence of primary heterogeneous nucleation followed by attrition-induced secondary nucleation. Results also evidence the nonmonotonic dependence of both induction time and mean crystal size on mixing intensity. Indeed, results show that the two parameters decrease with increasing mixing intensity at $\operatorname{Re}_{\mathrm{o}}$

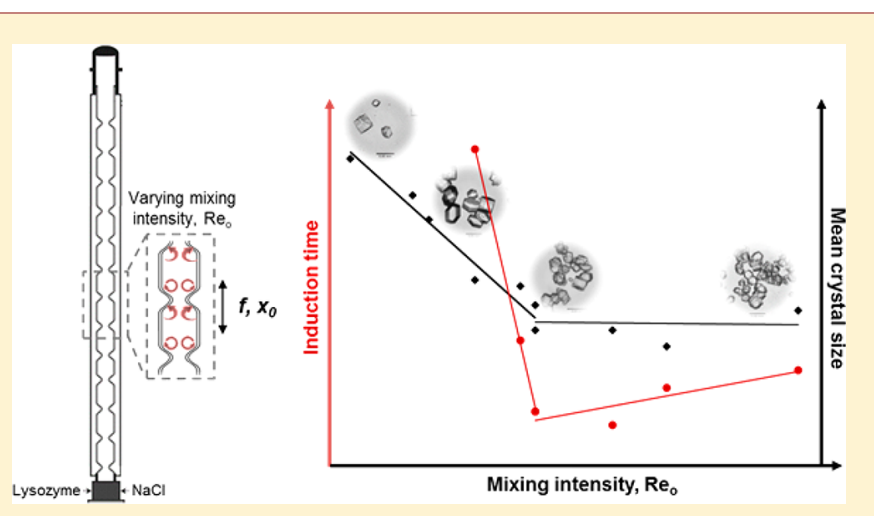
below 189, while for further increase of $\mathrm{Re}_{\mathrm{o}}$ both remain almost constant. Based on the literature, we suggest that such behavior may be explained by the influence of mixing intensity on protein clusters size distribution in solution. Further, induction time and mean crystal size show a stronger dependency on the oscillation amplitude compared to the oscillation frequency, in particular at the lower amplitudes. Finally, it is shown that lysozyme keeps its activity at the end of the experiments and crystal yields are quite reasonable.
\end{abstract}

\section{INTRODUCTION}

The rapidly expanding market for protein products has contributed to a business increase in the biotechnology industry. Indeed, proteins represent an important group of products from food and pharmaceuticals to cosmetics. ${ }^{1}$ Recent developments in more efficient upstream processes led to an improvement in the delivery of proteins amounts, shifting thus the manufacturing bottleneck toward the downstream process. The latter constitutes a substantial part of the overall cost and has to deal with several challenges, such as the increasing protein production and the achievement of high yield and purity with a reduced number of process units. ${ }^{2}$ Currently, downstream processing is mainly based on costly preparative chromatography steps. ${ }^{2-6}$ Therefore, alternative purification techniques must be established to meet the demands of an increasing market and reduce the costs during manufacturing.

In this context, protein crystallization can represent an alternative approach to the chromatography methodologies. ${ }^{6,7}$ Properly executed, protein crystallization operation can significantly reduce the number of steps in the downstream processing since it may be possible to obtain in a single-step high-purity proteins. Some processes with recovery yields higher than $95 \%$ were reported, namely, the case of $\beta$-amylase. ${ }^{3}$ Further, crystalline forms often have longer storage life and greater purity when compared to the dissolved form, opening up the range of application from formulation and storage of proteins to drug delivery. ${ }^{3,5,6,8}$ Despite its huge potential, there are still few crystallization processes implemented in the downstream process of proteins. One can cite the established purification processes of insulin, ${ }^{4}$ ovalbumin, ${ }^{9}$ lipase, ${ }^{10}$ elastase, ${ }^{11}$ and proteases I and II. ${ }^{12}$

Although there have been an increased number of published papers in protein crystallization for purification purposes in the last years, papers dedicated to well-defined and scalable processes are relatively scarce. Protein crystallization is a complex process in which there is no comprehensive theory, being hence mainly based on experimental data rather than theoretical insights. ${ }^{13}$ Usually the procedure involves an extensive series of crystallization trials that aims at optimizing the range of the individual variables that influence crystal formation. The many possible process conditions require substantial experimental work, and these must be evaluated individually for each protein and application case.

Research carried out so far has been focused on the study of protein crystallization in stirred tank batch reactors on the milliliter $(\mathrm{mL})$ to liter $(\mathrm{L})$ scale, although studies in different types of crystallizers, such as rotary shakers, ${ }^{14,15}$ devices with mechanical vibration, ${ }^{16}$ oscillatory flow ${ }^{17}$ or oscillatory flow

Received: May 10, 2018

Revised: September 7, 2018

Published: September 10, 2018 
mixing, ${ }^{18}$ and tubular reactors ${ }^{19}$ have been reported. Many of these works study the influence of the stirrer energy input and shear forces on nucleation, growth rate, crystal habit, and average crystal size. Gentle agitation is usually recommended in order to reduce crystal collisions with each other and/or parts of the crystallizer (wall, impeller) and fluid shear, minimizing hence secondary nucleation. ${ }^{20}$ However, it is important to maintain a minimum of agitation to ensure good mixing of the crystallization medium and keep the crystals suspended. ${ }^{8}$ According to the literature, the stirrer speed has been shown to have an important impact on crystallization onset time (nucleation), crystal size, and crystal aggregation. ${ }^{8,21}$ Concerning nucleation, reduction of the nucleation time was verified in unbaffled stirred vessels, ${ }^{9,21}$ in a wave shaker, $^{22}$ under oscillatory flow ${ }^{17}$ and oscillatory flow mixing ${ }^{18}$ when compared to nonagitated systems. As to crystal size and aggregation, most of the works report the decrease of mean crystal size and inhibition of aggregation with the increase of agitation. ${ }^{8,19}$ As for shear stress, several works have shown that shear inhibits nucleation, ${ }^{15,16,23,24}$ while others have shown that shear enhances nucleation. ${ }^{25}$ More recently, experiments, simulations and theories have shown that shear can either enhance or suppress nucleation depending on its magnitude, suggesting thereby the existence of an optimal shear flow leading to fastest nucleation. ${ }^{25-28}$

As mentioned above, protein crystallization operations are usually designed as stirred tank batch processes. However, large tanks are often characterized by low mixing efficiency that may lead to excess local concentrations and, consequently, affect the characteristics of the final product. Further, shear forces exerted by the impeller can be significant and thus be detrimental to protein crystallization. ${ }^{8}$ Therefore, a crystallizer with uniform mixing and minimized shear forces is desirable to overcome the aforementioned problems. In the present work, we report for the first time the influence of mixing intensity on protein crystallization in a meso oscillatory flow reactor (OFR) optimized by members of the present research team. ${ }^{29}$ The meso-OFR is a milliliter device where the common sharp baffles were replaced by smooth periodic constrictions (SPC) to reduce the high shear regions. ${ }^{30}$ Mixing intensity can be controlled by changing the oscillation frequency $(f)$ and amplitude $\left(x_{0}\right)$. Crystallization assays were carried out with a model protein, lysozyme. Lysozyme is one of the most popular model proteins as it easily crystallizes, allowing thus more systematic experimentation with view to set the optimum operating conditions for protein crystallization in the designed meso-OFR. Thereby, influence of mixing intensity on lysozyme crystallization, namely, nucleation, was evaluated by varying the oscillation $f$ and $x_{0}$. Turbidity of the crystallization solution was measured over time and the resulting crystals were characterized by optical microscopy. Additionally, crystal yield and activity were determined.

\section{MATERIALS AND METHODS}

Proteins and Chemicals. The protein and chemicals used, as well as the protocol for the preparation of the doubled concentrated lysozyme $\left(100 \mathrm{mg} \cdot \mathrm{mL}^{-1}\right)$ and sodium chloride $(6 \%(\mathrm{w} / \mathrm{v}))$ solutions are reported in a previous work. ${ }^{18}$ Both solutions were thermostatized at $20{ }^{\circ} \mathrm{C}$ and crystallization assays were started by their simultaneous injection in equal parts in the meso-OFR. In addition, lysozyme concentration was measured by UV spectroscopy (ScanSpec UV-vis, Sarspec, Portugal) at $280 \mathrm{~nm}$ using a known extinction coefficient (2.5 $\left.\mathrm{L} \cdot \mathrm{g}^{-1} \cdot \mathrm{cm}^{-1}\right) \cdot{ }^{31}$ Measurements were done at the beginning and at the end of each experiment to evaluate the lysozyme concentration in solution.

Experimental Installation. Lysozyme crystallization trials were carried out in the experimental setup represented in Figure 1. Except the oscillating system that consists in a linear motor (LinMot, Switzerland), the experimental installation is described in Castro et al.'s work. ${ }^{18}$

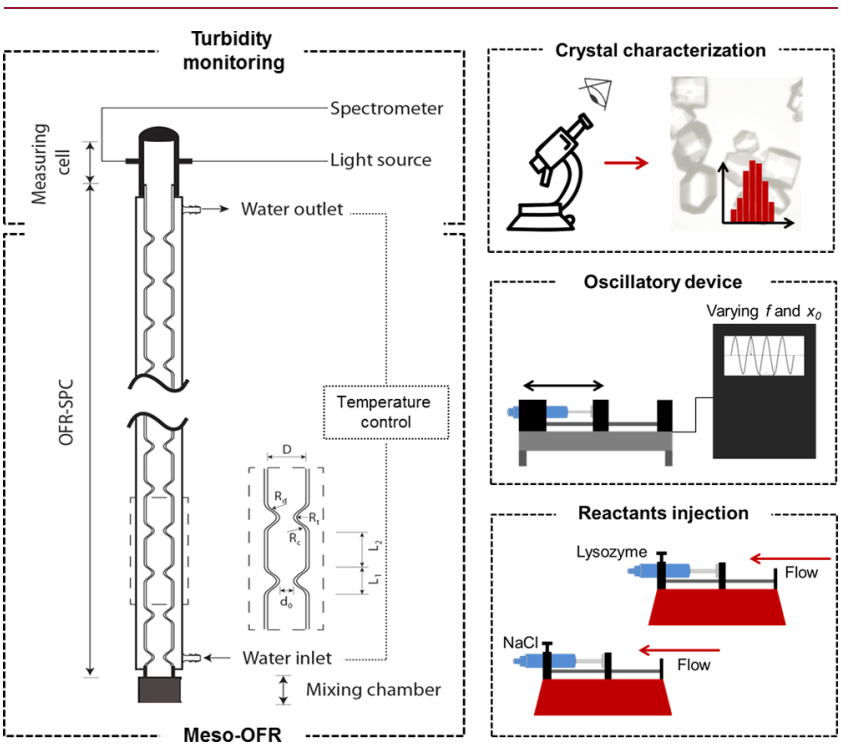

Figure 1. Schematic representation of the experimental setup for lysozyme crystallization experiments.

As mentioned before, the reactor is operated under oscillatory flow mixing, controlled by the oscillation frequency $(f)$ and amplitude $\left(x_{0}\right)$. The mixing intensity applied to the meso-OFR can be described by the oscillatory Reynolds number $\mathrm{Re}_{\mathrm{o}}:{ }^{2}$

$$
R e_{o}=\frac{2 \pi f x_{0} \rho d}{\mu}
$$

where $d$ is the column diameter $(\mathrm{m}), \rho$ the fluid density $\left(\mathrm{kg} \cdot \mathrm{m}^{-3}\right), \mu$ the fluid viscosity $\left(\mathrm{kg} \cdot \mathrm{m}^{-1} \cdot \mathrm{s}^{-1}\right), x_{0}$ the oscillation amplitude $(\mathrm{m})$, and $f$ the oscillation frequency $\left(\mathrm{s}^{-1}\right)$. Different mixing intensities were applied by varying $f$ and $x_{0}$ from 1.33 to $2.33 \mathrm{~Hz}$ and from 3.6 to 7.6 $\mathrm{mm}$, respectively. The value of the amplitude corresponds to the center-to-peak amplitude measured in the tube without constrictions. Reactants were fed into the setup by means of a syringe pump (NE4000, New Era, United States of America). Temperature inside the meso-OFR was regulated by a thermostatic bath (Huber, Ministat 125 , Germany) kept at $20^{\circ} \mathrm{C}$.

Turbidity Profile and Induction Time Measurement. Turbidity of the crystallization solution was monitored and induction time was measured following the methodology reported in Castro et al.'s work. ${ }^{18}$ Experiments lasted about $20 \mathrm{~h}$ and at least three replicates were done per experimental condition to assess the reproducibility of the experiments.

Assessment of Mean Crystal Size, Crystal Size Distribution and Morphology. Samples were collected at the end of the experiments, i.e., after $20 \mathrm{~h}$ (images not shown), and after reaching the maximum absorbance peak (the time at which samples were collected depends on the agitation conditions). Thereby, it was intended to assess the effect of mixing intensity on the crystals at a stage where most are already formed and thus prevent them from being exposed to prolonged agitation, which may cause their breakage and/or aggregation. The obtained crystals were characterized by optical microscopy (Standard 20, Zeiss, Germany) to evaluate their size, size distribution and morphology. Regarding mean crystal size and size distribution, a minimum of 500 crystals were analyzed (ImageJ) to ensure a reduced confidence interval smaller than $5 \%{ }^{33} \mathrm{It}$ 
is important to mention that mean crystal sizes and crystal size distributions were determined based on the measurement of the size of simple crystals.

Crystal Yield. Crystal yield was estimated based on the initial and final concentration of lysozyme in solution measured by spectrophotometry at $280 \mathrm{~nm}$ :

$$
\text { Yield }(\%)=\frac{C_{\text {lysozyme initial }}-C_{\text {lysozyme final }}}{C_{\text {lysozyme initial }}-C^{*}} \times 100
$$

where $\mathrm{C}^{*}$ is the lysozyme equilibrium concentration $\left(7.3 \mathrm{mg} \cdot \mathrm{mL}^{-1}\right.$ at $20{ }^{\circ} \mathrm{C}, \mathrm{pH} 4.7$, and $\left.\mathrm{NaCl} 3 \%(\mathrm{w} / \mathrm{v})\right)$, i.e., corresponds to the minimum concentration that can be reached and thus to the concentration for which the yield is maximum.

Lysozyme Enzymatic Activity. Enzymatic activity of the resulting lysozyme crystals and the initial lysozyme solution was determined by spectrophotometry through the measurement of the rate of lysis of Micrococcus lysodeikticus, as described in Castro et al.'s work. ${ }^{18}$

\section{RESULTS}

Monitoring of the Experiments by Turbidity Measurements. As shown in previous works, monitoring of the turbidity of the crystallization solution can provide a mean of detection of the different stages in protein crystallization. ${ }^{34,35}$ Figure 2 shows a typical turbidity profile obtained during the

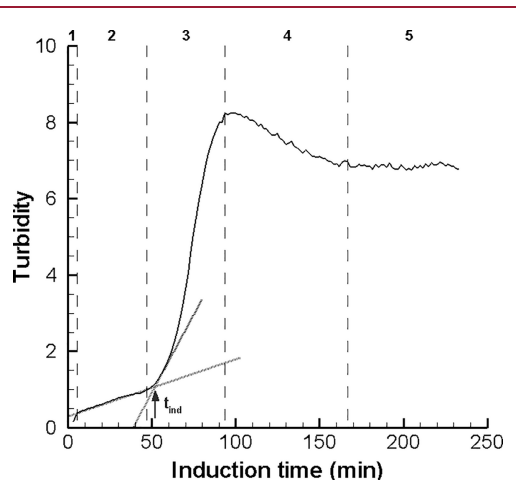

Figure 2. Turbidity profile during lysozyme crystallization in the meso-OFR at $20^{\circ} \mathrm{C}$ and $\mathrm{pH} 4.7$ for $x_{0}=7.6 \mathrm{~mm}$ and $f=2.33 \mathrm{~Hz}$ as an example.

lysozyme crystallization trials carried out. Initially (stage 1), a slight increase in the turbidity of the solution is observed, followed by a period where the turbidity remains almost constant (stage 2). This initial increase is thought to be due to the occurrence of a phenomenon prior to nucleation, probably the formation of protein clusters. ${ }^{36}$ In stage 3 , the turbidity increases sharply, which may be explained by the occurrence of both nucleation and crystal growth. Then the turbidity decreases (stage 4), which may be related with the sedimentation of the larger crystals and/or the aggregated smaller crystals. Finally, the turbidity stabilizes in stage 5, suggesting no significant formation of crystals.

In this way and as illustrated in Figure 2, the induction time $\left(t_{\text {ind }}\right)$ was considered as the time from the beginning of the experiment until the abrupt change of the absorbance, being derived by the intersect value, on the axis time, of the tangent to the first rapid increase in the turbidity profile curve. ${ }^{18,35}$ Consequently, the measured induction time does not correspond to the moment the nucleation occurs but to the moment at which the solution contains a certain amount of crystals.
It is also important to refer that for the experiments with the three lowest mixing intensities $\left(\operatorname{Re}_{\mathrm{o}}\right.$ 90: $f=1.33 \mathrm{~Hz}$ and $x_{0}=$ $3.6 \mathrm{~mm} . \operatorname{Re}_{\mathrm{o}} 123: f=1.83 \mathrm{~Hz}$ and $x_{0}=3.6 \mathrm{~mm}$. $\operatorname{Re}_{\mathrm{o}} 132: f=$ $1.33 \mathrm{~Hz}$ and $x_{0}=5.3 \mathrm{~mm}$ ), few crystals were formed and the solution remained clear. For those cases, no abrupt change in the turbidity profile was observed and it was not possible to determine the induction time with the methodology described.

Influence of Mixing Intensity on Induction Time. Based on the methodology described above, induction times were determined under different mixing conditions, except for the three experimental conditions with the lowest mixing intensities $\left(\mathrm{Re}_{\mathrm{o}}\right.$ of 90,123 and 132$)$, as previously mentioned. The measured induction times are plotted as a function of the mixing intensity $\left(\operatorname{Re}_{\mathrm{o}}\right)$ in the graph below.

According to Figure 3, the induction time decreases at first ( $\mathrm{Re}_{\mathrm{o}}$ from 157 to 189 ), reaching a minimum (at $\mathrm{Re}_{\mathrm{o}}$ of 189 ),

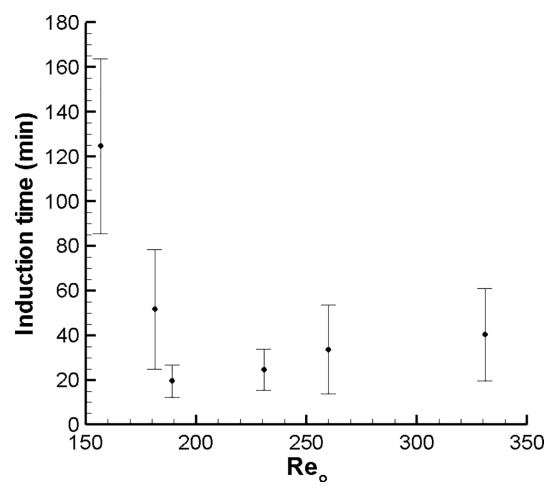

Figure 3. Induction time as a function of mixing intensity $\left(\operatorname{Re}_{\mathrm{o}}\right)$. The errors bars are standard deviations from at least three independent experiments.

after which it follows an increase ( $\operatorname{Re}_{\mathrm{o}}$ from 189 to 260$)$ into a plateau ( $\operatorname{Re}_{\mathrm{o}}$ from 260 to 331). The results suggest thus the existence of an optimal mixing intensity leading to a minimum induction time. One can also observe that the influence of mixing intensity on the induction time is more significant at lower mixing intensities $\left(\operatorname{Re}_{o}\right.$ of 157,181 , and 189) than at higher mixing intensities $\left(\operatorname{Re}_{\mathrm{o}}\right.$ of 231,260, and 331). A similar relationship between mixing intensity and induction time for the nucleation of butyl paraben under oscillatory flow mixing was reported by Yang et al. ${ }^{37}$ Authors verified that the induction time decreases with increasing mixing intensity for $\operatorname{Re}_{\mathrm{o}}$ below $\sim 200$ and starts to increase for $\operatorname{Re}_{\mathrm{o}}$ above $\sim 300$. Furthermore, they verified that primary nucleation phenomenon is more affected by shear rate at lower shear rates than at higher shear rates.

Figure $4 \mathrm{~A}$ shows the measured induction times as a function of the amplitude at fixed frequency, while Figure 4B shows the measured induction times as a function of the frequency at fixed amplitude.

Figure $4 \mathrm{~A}$ shows a clear decrease of the induction time with the increase of the amplitude from 3.6 to $5.3 \mathrm{~mm}$ at $2.33 \mathrm{~Hz}$, while no significant difference is observed with further increase of the amplitude from 5.3 to $7.6 \mathrm{~mm}$ at both 2.33 and $1.83 \mathrm{~Hz}$. In Figure $4 \mathrm{~B}$, it is possible to verify that the induction time does not significantly vary with increasing frequency at both 5.3 and $7.6 \mathrm{~mm}$. Therefore, results suggest a stronger influence of the oscillation amplitude on the induction time when compared to the oscillation frequency, especially at the lower amplitudes. 

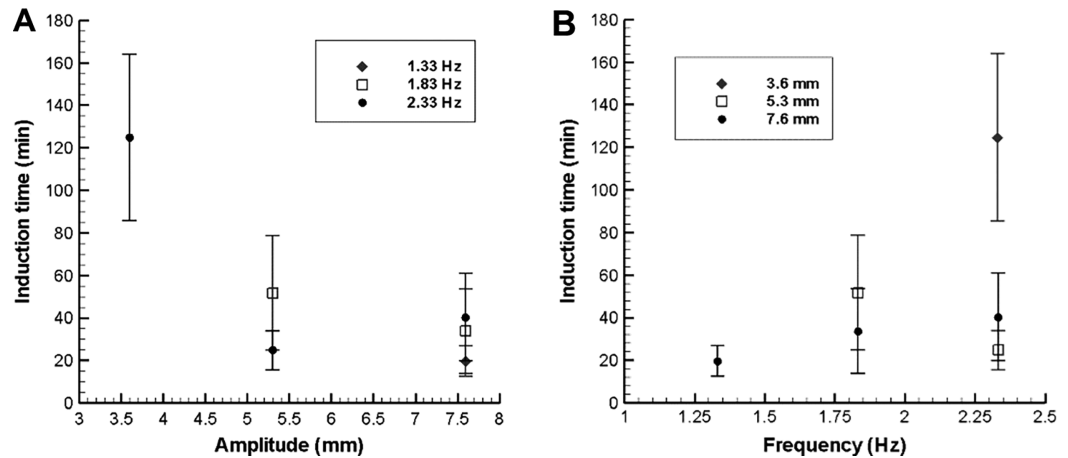

Figure 4. Induction time as a function of (A) oscillation amplitude at fixed frequency and (B) oscillation frequency at fixed amplitude. The errors bars are standard deviations from at least three independent experiments.

Influence of Mixing Intensity on Mean Crystal Size, Crystal Size Distribution and Morphology. Lysozyme crystals were collected for each experimental condition and observed by optical microscopy $(\times 10 \times 10)$, as shown in Figure 5. According to the images, all the samples are formed

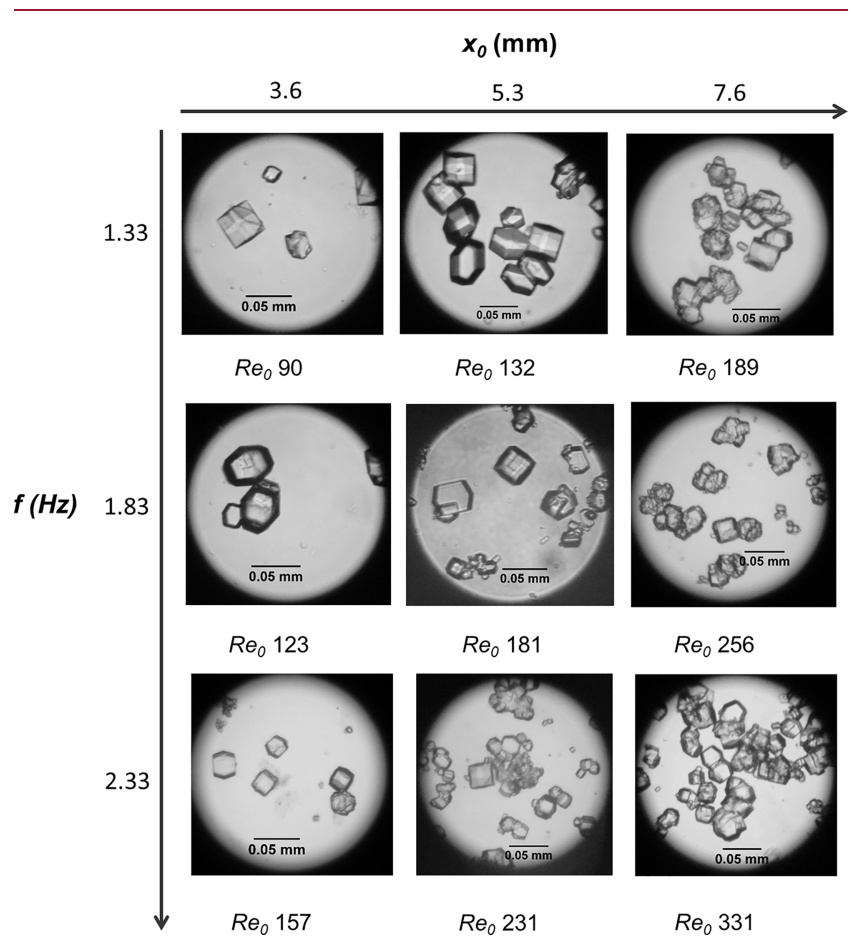

Figure 5. Images of the lysozyme crystals for the studied mixing intensities $\left(\mathrm{Re}_{\mathrm{o}}\right)$. by tetragonal crystals. The presence of crystals with different sizes for all the studied operating conditions is verified too. In general, and as further shown by the crystal size distribution results (Figure 6), mean crystal size seems to decrease with the increase of $x_{0}$ at a fixed $f$, as well as with the increase of $f$ at a fixed $x_{0}$. One also observes less but larger crystals at lower mixing intensities $\left(\mathrm{Re}_{\mathrm{o}}\right.$ from 90 to 181$)$ and more but smaller crystals at higher mixing intensities $\left(\mathrm{Re}_{\mathrm{o}}\right.$ from 189 to 331$)$. In addition, it seems that with increasing mixing intensity crystal size distribution is narrower, although this will be discussed in more details further on (Figure 6A,B). Figure 5 also evidences the aggregation of lysozyme crystals, particularly for the highest mixing intensities $\left(\mathrm{Re}_{\mathrm{o}}\right.$ from 189). According to the literature, ${ }^{38}$ aggregation of lysozyme crystals with a diameter in the range of $1-50 \mu \mathrm{m}$ is mostly due to shear forces. In this way, the aggregation of lysozyme crystals can be justified by their small size (approximately between 10 to $20 \mu \mathrm{m}$, see Figure 6 and Table 1) and by the fact that they were subjected to shear forces, which promote collisions between crystals and thereby their aggregation.

Based on the optical microscopy images of the crystals, crystal size distribution and mean crystal size were determined by image analysis for a total of at least 500 simple crystals for each experimental condition, so that the results do not consider aggregates. Figure $6 \mathrm{~A}$ and $6 \mathrm{~B}$ show the influence of mixing intensity on lysozyme crystal size distribution and mean crystal size, respectively.

According to Figure $6 \mathrm{~A}$, the general trend is that lysozyme crystals are smaller and more uniform in size as mixing intensity increases. In what concerns Figure $6 \mathrm{~B}$, it evidences the decrease of lysozyme mean crystal size with the increase of mixing intensity for $\mathrm{Re}_{\mathrm{o}}$ from 90 until 189, from which mean
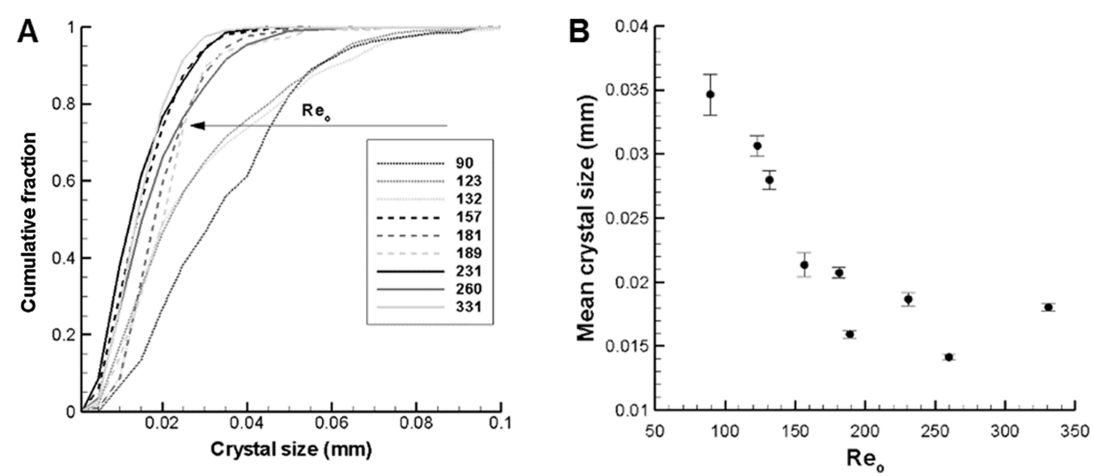

Figure 6. Influence of mixing intensity $\left(\mathrm{Re}_{\mathrm{o}}\right)$ on $(\mathrm{A})$ lysozyme crystal size distribution and (B) lysozyme mean crystal size. 
Table 1. Summary of the Experimental Results for the Lysozyme Crystallization Trials Performed in the Meso-OFR

\begin{tabular}{|c|c|c|c|c|c|c|c|c|}
\hline$x_{0}(\mathrm{~mm})$ & $f(\mathrm{~Hz})$ & $\operatorname{Re}_{0}$ & $t_{\text {ind }}(\min )$ & $\operatorname{error}^{a}(\mathrm{~min})$ & mean crystal size $(\mu \mathrm{m})$ & error $^{b}(\mu \mathrm{m})$ & yield (\%) & relative activity (\%) \\
\hline \multirow[t]{3}{*}{3.6} & 1.33 & 90 & & & 34.6 & 1.6 & 75 & $>74$ \\
\hline & 1.83 & 123 & & & 30.6 & 0.8 & 72 & \\
\hline & 2.33 & 157 & 124 & 39 & 21.3 & 0.9 & 73 & \\
\hline \multirow[t]{3}{*}{5.3} & 1.33 & 132 & & & 28.0 & 0.7 & 72 & $>89$ \\
\hline & 1.83 & 181 & 52 & 27 & 20.7 & 0.4 & 89 & \\
\hline & 2.33 & 231 & 25 & 9 & 18.6 & 0.5 & 94 & \\
\hline \multirow[t]{3}{*}{7.6} & 1.33 & 189 & 20 & 7 & 15.9 & 0.3 & 77 & $>67$ \\
\hline & 1.83 & 260 & 34 & 20 & 14.1 & 0.2 & 64 & \\
\hline & 2.33 & 331 & 40 & 21 & 18.0 & 0.3 & 82 & \\
\hline
\end{tabular}

${ }^{a}$ The errors bars are standard deviations from at least three independent experiments. ${ }^{b}$ The error correspond to the standard error of the sample mean.
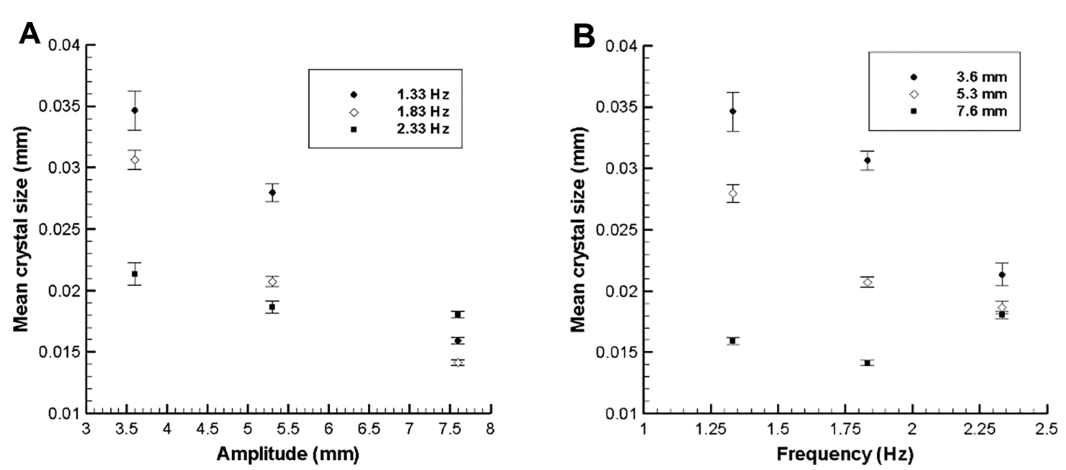

Figure 7. Lysozyme mean crystal size as a function of (A) oscillation amplitude at fixed frequency and (B) oscillation frequency at fixed amplitude. The error bars correspond to the standard error of the sample mean.

crystal size remains almost constant with further increase of mixing intensity. In the opposite, literature reports the decrease of lysozyme average crystal size with the increase of the power input in a stirred tank crystallizer. ${ }^{8}$ This was also observed for the crystallization of L-glutamic acid in an oscillatory baffled crystallizer, where mean crystal size decreases with the increase of the oscillatory Reynolds number. ${ }^{39}$

Figure 7A shows that lysozyme mean crystal size decreases as the oscillation amplitude increases regardless of the oscillation frequency. It is also verified that as the amplitude increases the difference between the mean crystal sizes for the three studied frequencies is smaller. As to Figure $7 \mathrm{~B}$, the tendency is that lysozyme mean crystal size decreases as the oscillation frequency increases for the three studied oscillation amplitudes. It is also shown that for the same frequency mean crystal sizes are quite different depending on the amplitude value, unless for the highest frequency where mean crystal sizes are similar regardless of the amplitude. According to these results, it seems that the oscillation amplitude has a higher influence on lysozyme mean crystal size when compared to the oscillation frequency, namely at the lower amplitudes.

Yield and Activity. According to Table 1, formed crystals kept their activity at the end of the experiments as activity values were superior to $67 \%$, with an experimental error of about $12 \%$. Regarding crystal yield, values are above $60 \%$ for all the studied operating conditions, error associated with its determination being approximately $11 \%$. It is important to remember that yield was estimated based on lysozyme concentration measured by absorbance. Several dilutions had to be made, which may entail errors when estimating crystal yield.

\section{DISCUSSION}

Given the operating conditions and as suggested by the experimental results, it is though that both primary heterogeneous nucleation ${ }^{40}$ and attrition-induced secondary nucleation $^{20,41}$ may have contributed to the nucleation mechanism. Indeed, the rapid increase in turbidity shown in Figure 2 suggests the formation of a large number of crystals in a short time scale, which has been related in previous works ${ }^{42-45}$ with the occurrence of secondary nucleation rather than a sudden increase in primary nucleation. In addition, Figure 5 evidences the presence of crystals with different sizes for all the operating conditions. Though it is not possible to distinguish secondary nuclei grown crystals from primary grown crystals, this observation may indicate the occurrence of secondary nucleation. While damaged crystals and/or fragments were not observed since crystals were collected at the end of stage 3 (Figure 2), and at the end of the experiments, it has been reported that for lysozyme crystallization in agitated systems secondary nucleation likely results from attrition. ${ }^{46}$ Based on this hypothesis, the measured induction time may be related not only with the time required for primary nuclei to form and grow to a detectable size, but also with the time required for secondary nuclei to form and grow to a sufficient size to be detected. ${ }^{44,45}$

As expected and corroborated by the experimental results on the influence of mixing intensity on both induction time (Figure 3) and mean crystal size (Figure 6), nucleation behavior of lysozyme in the meso-OFR is affected by the mixing intensity. At $\operatorname{Re}_{\mathrm{o}}$ between 157 and 189, both induction time and mean crystal size clearly decrease with increasing mixing intensity, while at $\operatorname{Re}_{\mathrm{o}}$ between 189 and 331, influence of mixing intensity on both induction time and crystal size is 
less significant. The decrease of both induction time and mean crystal size with increasing mixing intensity at $157 \leq \mathrm{Re}_{\mathrm{o}} \leq 189$ may be related with the fact that nuclei growth is promoted due to the flow-induced advective transport to the cluster, enhancing thus primary nucleation. ${ }^{26}$ Molecular alignment induced by shear has also been reported as a potential explanation for enhanced primary nucleation. ${ }^{41,47}$ An alternative explanation is the increase of secondary nucleation rate from grown primary crystals due to an increase of crystal collisions and subsequent increase in the rate of attrition, causing the detectable amount of crystals to be reached earlier. This is in agreement with Tait study, ${ }^{46}$ where stirring speed was shown to affect significantly lysozyme secondary nucleation rate, which is consistent with a contact/attrition based model of secondary nucleation. Regarding higher mixing intensities $\left(189 \leq \mathrm{Re}_{\mathrm{o}} \leq 331\right)$, induction time and mean crystal size remain almost constant with increasing mixing intensity, suggesting that the nucleation rate remains constant. In what concerns primary nucleation, literature reports that high shear rates can cause the breakup of the protein clusters ${ }^{26}$ and thereby reduce primary nucleation rate. In relation to secondary nucleation, it seems that from $\mathrm{Re}_{\mathrm{o}}$ of 189 additional increase of mixing intensity has no longer influence on secondary nucleation rate since mean crystal size remains almost constant. This is also corroborated by the crystal size distribution results, as a narrowing of the crystal size distribution is verified for $\mathrm{Re}_{\mathrm{o}}$ above 189. This can be due to the fact that the formed primary crystals are not large enough to promote the formation of attrition-induced nuclei. Indeed, large crystals are more likely to collide with each other than small crystals and thereby are more prone to attrition. ${ }^{48}$

Results also show a higher influence of the oscillation amplitude compared to the frequency on both induction time (Figure 4) and mean crystal size (Figure 6), especially at the lower amplitudes $(3.6$ and $5.3 \mathrm{~mm}$ ). This can be explained by the fluid patterns in meso oscillatory flow reactors, where previous studies and simulations on the influence of the oscillation frequency and amplitude have demonstrated a greater influence of the amplitude on fluid mixing since the amplitude controls the length of eddy generated in the column. ${ }^{30,49,50}$

\section{CONCLUSION}

Influence of mixing intensity on lysozyme crystallization is reported for the first time in a meso oscillatory flow reactor (meso-OFR). Although further evaluation of the nucleation behavior is needed, results suggest that both primary and attrition-induced secondary nucleation may have contributed to the crystallization mechanism. Results also show a nonmonotonic dependence of both induction time and mean crystal size on mixing intensity, evidencing the existence of an optimum oscillatory Reynolds number $\left(\mathrm{Re}_{\mathrm{o}}\right)$ that leads to a faster nucleation. This may be attributed to the influence of mixing intensity on the size distribution of protein clusters in solution. Depending on its magnitude, mixing intensity may, on the one hand, promote both protein clusters growth and attrition-induced secondary nuclei formation or, on the other hand, lead to protein cluster breakup. In relation to the individual influence of oscillation amplitude and frequency, induction time and mean crystal size show a stronger dependency on the amplitude compared to the frequency. This is probably due to the predominant role of the oscillation amplitude in fluid mixing. Finally, it is shown that lysozyme remains active at the end of the experiments and crystal yields are above $60 \%$ for all the operating conditions.

Though further investigation is needed, the present study may provide important insights regarding the understanding of the lysozyme crystallization mechanism under oscillatory flow mixing. In particular, results open the potential to exploit meso-OFRs to control protein nucleation for the design of protein crystallization as a process step.

\section{AUTHOR INFORMATION}

\section{Corresponding Author}

*Tel: +35122 50816 87. E-mail: filipaj@fe.up.pt. ORCID $\odot$

Filipa Castro: 0000-0001-7447-4063

Notes

The authors declare no competing financial interest.

\section{ACKNOWLEDGMENTS}

This work was the result of the project: (i) POCI-01-0145FEDER-016816 (PTDC/QEQ-PRS/3787/2014) funded by the European Regional Development Fund (ERDF), through COMPETE2020, Programa Operacional Competitividade e Internacionalização (POCI), and by national funds through Fundação para a Ciência e a Tecnologia (FCT), Project 9471, Reforçar a Investigação, o Desenvolvimento, Tecnológico e a Inovação (Projeto 9471, RIDTI); (ii) POCI-01-0145-FEDER006939 (Laboratory for Process Engineering, Environment, Biotechnology and Energy, UID/EQU/00511/2013) funded by the European Regional Development Fund (ERDF), through COMPETE2020, Programa Operacional Competitividade e Internacionalização (POCI), and by national funds, through FCT, Fundação para a Ciência e a Tecnologia; (iii) NORTE-01-0145-FEDER-000005-LEPABE-2-ECO-INNOVATION, supported by North Portugal Regional Operational Programme (NORTE 2020), under the Portugal 2020 Partnership Agreement, through the European Regional Development Fund (ERDF); (iv) UID/BIO/04469/2013, IF exploratory project [IF/01087/2014], and Postdoctoral Fellowship [SFRH/BPD/96132/2013]. A.F. is an Investigador FCT.

\section{REFERENCES}

(1) Labrou, N. E. Protein Purification: An Overview. In Protein Downstream Processing. Methods in Molecular Biology (Methods and Protocols); Labrou, N., Ed.; Humana Press: Totowa, NJ, 2014; Vol. 1129, pp 3-10.

(2) dos Santos, R.; Carvalho, A. L.; Roque, A. C. A. Renaissance of Protein Crystallization and Precipitation in Biopharmaceuticals Purification. Biotechnol. Adv. 2017, 35, 41-50.

(3) Lee, E. K.; Kim, W. Protein Crystallization for Large-Scale Bioseparation. In Isolation and Purification of Proteins; Hatti-Kaul, R., Mattiasson, B., Eds.; CRC Press: New York, 2003.

(4) Thömmes, J.; Etzel, M. Alternatives to Chromatographic Separations. Biotechnol. Prog. 2007, 23, 42-45.

(5) Hebel, D. P. Protein Crystallization in Stirred-Tank Reactors. Ph.D. thesis, Technische Universität München, 2013.

(6) Hekmat, D. Large-Scale Crystallization of Proteins for Purification and Formulation. Bioprocess Biosyst. Eng. 2015, 38, $1209-1231$.

(7) Navarro, A.; Wu, H.-S.; Wang, S. S. Engineering Problems in Protein Crystallization. Sep. Purif. Technol. 2009, 68, 129-137.

(8) Schmidt, S.; Havekost, D.; Kaiser, K.; Kauling, J.; Henzler, H.-J. Crystallization for the Downstream Processing of Proteins. Eng. Life Sci. 2005, 5, 273-276. 
(9) Judge, R. A.; Johns, M. R.; White, E. T. Protein Purification by Bulk Crystallization: The Recovery of Ovalbumin. Biotechnol. Bioeng. 1995, 48, 316-323.

(10) Jacobsen, C.; Garside, J.; Hoare, M. Nucleation and Growth of Microbial Lipase Crystals from Clarified Concentrated Fermentation Broths. Biotechnol. Bioeng. 1998, 57, 666-675.

(11) Lewis, U. J.; Williams, D. E.; Brink, N. G. Pancreatic Elastase: Purification, Properties, and Function. J. Biochem. 1956, 222, 705720.

(12) Srivastava, O. P.; Aronson, A. I. Isolation and Characterization of a Unique Protease from Sporulating Cells of Bacillus Subtilis. Arch. Microbiol. 1981, 129, 227-232.

(13) McPherson, A.; Gavira, J. A. Introduction to Protein Crystallization. Acta Crystallogr., Sect. F: Struct. Biol. Commun. 2014, F70, 2-20.

(14) Hekmat, D.; Hebel, D.; Schmid, H.; Weuster-Botz, D. Crystallization of Lysozyme: From Vapor Diffusion Experiments to Batch Crystallization in Agitated Ml-Scale Vessels. Process Biochem. 2007, 42, 1649-1654.

(15) Murai, R.; Yoshikawa, H. Y.; Kawahara, H.; Maki, S.; Sugiyama, S.; Kitatani, T.; Adachi, H.; Takano, K.; Matsumura, H.; Murakami, S.; et al. Effect of Solution Flow Produced by Rotary Shaker on Protein Crystallization. J. Cryst. Growth 2008, 310, 2168-2172.

(16) Lu, Q.-Q.; Yin, D. C.; Liu, Y. M.; Wang, X. K.; Yang, P. F.; Liu, Z. T.; Shang, P. Effect of Mechanical Vibration on Protein Crystallization. J. Appl. Crystallogr. 2010, 43, 473-482.

(17) Parambil, J. V.; Schaepertoens, M.; Williams, D. R.; Heng, J. Y. Y. Effects of Oscillatory Flow on the Nucleation and Crystallization of Insulin. Cryst. Growth Des. 2011, 11, 4353-4359.

(18) Castro, F.; Ferreira, A.; Teixeira, J. A.; Rocha, F. Protein Crystallization As a Process Step in a Novel Meso Oscillatory Flow Reactor: Study of Lysozyme Phase Behavior. Cryst. Growth Des. 2016, $16,3748-3755$.

(19) Neugebauer, P.; Khinast, J. G. Continuous Crystallization of Proteins in a Tubular Plug-Flow Crystallizer. Cryst. Growth Des. 2015, 15, 1089-1095.

(20) Agrawal, S. G.; Paterson, A. H. J. Secondary Nucleation: Mechanisms and Models. Chem. Eng. Commun. 2015, 202, 698-706.

(21) Smejkal, B.; Helk, B.; Rondeau, J.-M.; Anton, S.; Wilke, A.; Scheyerer, P.; Fries, J.; Hekmat, D.; Weuster-Botz, D. Protein Crystallization in Stirred Systems-Scale-up via the Maximum Local Energy Dissipation. Biotechnol. Bioeng. 2013, 110, 1956-1963.

(22) Yaoi, M.; Adachi, H.; Takano, K.; Matsumura, H.; Inoue, T.; Mori, Y.; Sasaki, T. Effect of Stirring Method on Protein Crystallization. Jpn. J. Appl. Phys. 2004, 43, 1318.

(23) Pusey, M.; Witherow, W.; Naumann, R. Preliminary Investigations into Solutal Flow about Growing Tetragonal Lysozyme Crystals. J. Cryst. Growth 1988, 90, 105-111.

(24) Vekilov, P. G.; Rosenberger, F. Protein Crystal Growth under Forced Solution Flow: Experimental Setup and General Response of Lysozyme. J. Cryst. Growth 1998, 186, 251-261.

(25) Penkova, A.; Pan, W.; Hodjaoglu, F.; Vekilov, P. G. Nucleation of Protein Crystals under the Influence of Solution Shear Flow. Ann. N. Y. Acad. Sci. 2006, 1077, 214-231.

(26) Mokshin, A. V.; Galimzyanov, B. N.; Barrat, J. L. Extension of Classical Nucleation Theory for Uniformly Sheared Systems. Phys. Rev. E Stat Nonlin Soft Matter Phys. 2013, 87, 62307.

(27) Mura, F.; Zaccone, A. Effects of Shear Flow on Phase Nucleation and Crystallization. Phys. Rev. E: Stat. Phys., Plasmas, Fluids, Relat. Interdiscip. Top. 2016, 93, 42803.

(28) Byington, M. C.; Safari, M. S.; Conrad, J. C.; Vekilov, P. G. Shear Flow Suppresses the Volume of the Nucleation Precursor Clusters in Lysozyme Solutions. J. Cryst. Growth 2017, 468, 493-501.

(29) Ferreira, A.; Rocha, F.; Teixeira, J. A.; Vicente, A. Apparatus for Mixing Improvement Based on Oscillatory Flow Reactors Provided with Smooth Periodic Constrictions. WO/2015/056156, 2014.

(30) Reis, N. M. F. Novel Oscillatory Flow Reactors for Biotechnological Applications. Ph.D. thesis, Universidade do Minho, 2006.
(31) Smejkal, B.; Agrawal, N. J.; Helk, B.; Schulz, H.; Giffard, M.; Mechelke, M.; Ortner, F.; Heckmeier, P.; Trout, B. L.; Hekmat, D. Fast and Scalable Purification of a Therapeutic Full-Length Antibody Based on Process Crystallization. Biotechnol. Bioeng. 2013, 110, 24522461.

(32) Harvey, A. P.; Mackley, M. R.; Stonestreet, P. Operation and Optimization of an Oscillatory Flow Continuous Reactor. Ind. Eng. Chem. Res. 2001, 40, 5371-5377.

(33) Faria, N.; Pons, M. N.; Feyo de Azevedo, S.; Rocha, F. A.; Vivier, H. Quantification of the Morphology of Sucrose Crystals by Image Analysis. Powder Technol. 2003, 133, 54-67.

(34) Biscans, B.; Laguerie, C. Determination of Induction Time of Lysozyme Crystals by Laser Diffraction. J. Phys. D: Appl. Phys. 1993, 26, B118.

(35) Hu, H.; Hale, T.; Yang, X.; Wilson, L. J. A SpectrophotometerBased Method for Crystallization Induction Time Period Measurement. J. Cryst. Growth 2001, 232, 86-92.

(36) Manuel García-Ruiz, J. Nucleation of Protein Crystals. J. Struct. Biol. 2003, 142, 22-31.

(37) Yang, H.; Yu, X.; Raval, V.; Makkawi, Y.; Florence, A. Effect of Oscillatory Flow on Nucleation Kinetics of Butyl Paraben. Cryst. Growth Des. 2016, 16, 875-886.

(38) Kwon, J. S.-I.; Nayhouse, M.; Christofides, P. D.; Orkoulas, G. Modeling and Control of Shape Distribution of Protein Crystal Aggregates. Chem. Eng. Sci. 2013, 104, 484-497.

(39) Ni, X.; Liao, A. Effects of Mixing, Seeding, Material of Baffles and Final Temperature on Solution Crystallization of L-Glutamic Acid in an Oscillatory Baffled Crystallizer. Chem. Eng. J. 2010, 156, $226-233$.

(40) Hodzhaoglu, F. V.; Nanev, C. N. Heterogeneous versus Bulk Nucleation of Lysozyme Crystals. Cryst. Res. Technol. 2010, 45, 281291.

(41) Liu, J.; Svärd, M.; Rasmuson, Å. C. Influence of Agitation on Primary Nucleation in Stirred Tank Crystallizers. Cryst. Growth Des. 2015, 15, 4177-4184.

(42) Mullin, J. W. Crystallization, 4th ed.; Butterworth Heinemann: Oxford, 2001.

(43) Kobari, M.; Kubota, N.; Hirasawa, I. Secondary NucleationMediated Effects of Stirrer Speed and Growth Rate on Induction Time for Unseeded Solution. CrystEngComm 2012, 14, 5255-5261.

(44) Kadam, S. S.; Kramer, H. J. M.; ter Horst, J. H. Combination of a Single Primary Nucleation Event and Secondary Nucleation in Crystallization Processes. Cryst. Growth Des. 2011, 11, 1271-1277.

(45) Forsyth, C.; Mulheran, P. A.; Forsyth, C.; Haw, M. D.; Burns, I. S.; Sefcik, J. Influence of Controlled Fluid Shear on Nucleation Rates in Glycine Aqueous Solutions. Cryst. Growth Des. 2015, 15, 94-102.

(46) Tait, S.; White, E. T.; Litster, J. D. A Study on Nucleation for Protein Crystallization in Mixed Vessels. Cryst. Growth Des. 2009, 9, 2198-2206.

(47) Yang, H.; Yu, X.; Raval, V.; Makkawi, Y.; Florence, A. Effect of Oscillatory Flow on Nucleation Kinetics of Butyl Paraben. Cryst. Growth Des. 2016, 16, 875-886.

(48) Cruz, P.; Rocha, F.; Ferreira, A. Determination of the Critical Mixing Intensity for Secondary Nucleation of Paracetamol in an Oscillatory Flow Crystallizer. CrystEngComm 2018, 20, 829-836.

(49) Reis, N.; Harvey, A.; Mackley, M. R.; Vicente, A. A.; Teixeira, J. A. Fluid Mechanics and Design Aspects of a Novel Oscillatory Flow Screening Mesoreactor. Chem. Eng. Res. Des. 2005, 83, 357-371.

(50) Phan, A. N.; Harvey, A.; Lavender, J. Characterisation of Fluid Mixing in Novel Designs of Mesoscale Oscillatory Baffled Reactors Operating at Low Flow Rates $(0.3-0.6 \mathrm{~mL} / \mathrm{min})$. Chem. Eng. Process. 2011, 50, 254-263. 